\title{
Interactive comment on "Estimation of Evapotranspiration and Other Soil Water Budget Components in an Irrigated Agricultural Field of a Desert Oasis, Using Soil Moisture Measurements" by Zhongkai Li et al.
}

\section{Anonymous Referee \#1}

Received and published: 23 April 2019

The manuscript uses timeseris of soil moisture data to estimate the soil water budget components, especially evapotranspiration, in an irrigated agricultural filed of a desert oasis. This study is well conducted, and the authors responded the comments well. I think it is worth publishing after minor revisions. I have several comments listed as below.

1. The anonymous reviewer 3\# concerns the locations of Secion 3.1, 3.2, and 3.3, and the authors insisted the former locations. I think the problem may be arisen by the title of them. The current titles may be misleading to about the dataset, nor the observed 
or calculated results. For example, Section 3.2 is about calculated irrigation amount. The meteorological data should be introduced in the materials section.

2. I am confused by the Sstop and Smax. Is Sstop larger than Smax, as shown in Fig. 2.

3. Please check the captions appeared in the text. For example, Fig.7 appears early than Fig. 5. Where is Fig. 6?

4. Fig.3, It is better to shown the specific irrigation amount and compare it with rainfall event.

Interactive comment on Hydrol. Earth Syst. Sci. Discuss., https://doi.org/10.5194/hess-201989, 2019. 